\title{
Cerebral cortical capillary basement membrane thickening in galactosaemic rats
}

\author{
R. N. Frank, S.Dutta and S.E. Frank \\ The Kresge Eye Institute of Wayne State University School of Medicine, Detroit, Michigan, USA
}

\begin{abstract}
Summary. Wistar-Kyoto rats fed a diet containing $30 \%$ by weight galactose for 15-21 months developed significant thickening of the endothelial basement membranes of capillaries from the frontal cortex of the cerebrum, by comparison with cerebral capillary basement membranes from animals on a standard diet $(p<0.001)$, or animals receiving a diet containing 30\% galactose together with $250 \mathrm{mg} / \mathrm{kg}$ diet of the aldose reductase inhibitor, Sorbinil $(0.001<p<0.01)$. The effect was similar to that which we have reported previously in the retinal capillaries of these animals. Spontaneously hypertensive rats on the high-galactose diet showed modest cerebral capillary basement membrane thickening $(0.02<p<$ 0.05 ) only for one of the measurement protocols utilised, and the process was not prevented by Sorbinil. Biochemical assays of retina, cerebral cortex, and blood serum from WistarKyoto and spontaneously hypertensive rats maintained on the Sorbinil regimen showed that the drug did cross the blood-retinal and blood-brain barriers. Similar to our previous study on the retinal capillaries, we observed no degener-
\end{abstract}

ation of pericyte or endothelial cell cytoplasm, and no alteration in the pericyte/endothelial cell nuclear ratio in the cerebral capillaries of galactosaemic animals, by comparison with controls. Based on immunocytochemical studies in the human retina, it has been claimed that aldose reductase is present in capillary pericytes but absent in the endothelial cells. However, we observe a considerably smaller pericyte/ endothelial cell nuclear ratio in the capillaries of the cerebral cortex of the rat, by comparison with those of the retina. Also, pericyte coverage of the cerebral cortical capillaries is much less than that of the retinal capillaries of these animals. Therefore, it appears that the biochemical process(es) responsible for basement membrane thickening are unlikely to reside within the pericytes.

Key words: Basement membrane thickening, galactosaemia, aldose reductase inhibitors, endothelial cells, pericytes, microvessels, cerebral cortex, morphometry.
Diabetes mellitus has been reported to cause thickening of basement membranes in many organs and tissues, both in spontaneously diabetic humans [1-6] and in spontaneously and experimentally diabetic animals [7-10]. Recently, we [11] and others [12-13] have reported thickening of retinal capillary basement membranes in galactosaemic rats that was prevented by simultaneous administration of an aldose reductase inhibitor. These studies, together with the finding that chronically galactosaemic dogs demonstrate retinal capillary pericyte loss, capillary acellularity, and microaneurysm formation, similar to that found in chronically diabetic dogs and humans [14], suggests a role for the "sorbitol pathway" in the pathogenesis of diabetic retinopathy. In the present paper, we demonstrate that chronically galactosaemic rats also develop thickening of the cerebral cortical capillaries. This indicates that basement membrane thickening induced by experimental galactosaemia, like that caused by diabetes mellitus, is a generalised lesion and is not restricted to a single organ. Also, the lesion in the cerebral cortical capillaries of Wistar-Kyoto (WKy) rats is prevented by the aldose reductase inhibitor Sorbinil (d-6-fluorospiro[chroman-4,4'-imidazoline]-2', $5^{\prime}$-dione; CP-45634, obtained from Dr. M.Peterson, Pfizer Central Research, Groton, Conn, USA). However, unlike our previous study on the retinal capillaries, we have not observed prevention of galactose-induced cerebral capillary basement membrane thickening by Sorbinil in spontaneously hypertensive (SHR) rats.

\section{Materials and methods}

\section{Animal maintenance}

Animals used in these experiments were those described in an earlier paper dealing with retinal capillary basement membrane thickening in galactosaemic rats [11]. These were Wistar-Kyoto (normotensive, designated WKy) female albino rats, initiated into the dietary protocol at 6 weeks postnatal age, body weight about $100 \mathrm{~g}$; and spon- 
taneously hypertensive (designated SHR) female albino rats entered into the protocol at the same age. All animals were obtained from Taconic Farms, Germantown, NY, USA. A description of the standard diet, galactosaemic (30\% by weight) diet, 30\% galactose-plusSorbinil $(250 \mathrm{mg} / \mathrm{kg}$ ) diet and other aspects of animal care have been described previously [11]. It had been our original intention to maintain all animals on the experimental regimens for 2 years. However, because of mortality during the course of the study we terminated the experiment after 21 months. Animals that were entered into the study to replace those that died were not maintained for a full 21 months. Hence, at the conclusion of the study we had four 15-month and three 21-month old WKy controls; four 15-month and three 21-month old galactose-fed WKy rats; three 15-month and three 21-month old galactose-plus-Sorbinil-fed WKy rats; two 15-month and three 17-month old SHR controls; one 15-month and two 17-month old SHR rats fed galactose; and three 15-month and three 17-month old galactose-plus-Sorbinil-fed SHR rats.

\section{Electron microscopy}

After the animals had been on the diets for 15-21 months, they were killed by ether anaesthesia followed by exsanguination by cardiac puncture. After opening the skull, cubes of cerebral cortex approximately $1 \mathrm{~mm}$ on a side were cut freehand from the frontal region of either hemisphere, and were fixed by immersion in 3\% glutaraldehyde buffered with $0.1 \mathrm{~mol} / 1$ cacodylate, $\mathrm{pH} 7.3$, at $26^{\circ} \mathrm{C}$ for $1 \mathrm{~h}$. Further details of postfixation in $\mathrm{OsO}_{4}$, dehydration, embedding, staining and thin-sectioning have been described previously [11]. Some cortical tissues were inadvertently not collected; hence, numbers of animals in several groups are smaller than those reported earlier in our study on retinal capillaries [11]. This is particularly notable in the galactosaemic, SHR group, which is comprised of only 3 of the original 6 animals in the present study. Capillaries were identified as vessels whose lumen was lined by not more than two endothelial cells surrounded by a basement membrane. Although we did not make detailed comparisons of basement membrane thickness between capillaries of different cortical layers, our general impression was that these did not differ greatly. The vessels used in this study were taken from no deeper than approximately $1 \mathrm{~mm}$ (the thickness of each free-hand cut tissue block) from the surface of the frontal cortex. However, throughout this study, we did not distinguish between capillaries from different levels within this thickness of tissue. The vessels were observed on a Philips 300 transmission electron microscope, photographed at a standard magnification of 7,500 X (checked daily by photographing calibration grids), and enlarged to a final magnification of $18,000 \mathrm{X}$ when the negatives were printed. Prior to measurement by an observer, the prints were labelled with code numbers, so that the observer was unaware of the animal from which they were taken. Basement membrane thickness was measured using the BioQuant software package (R\&M Biometrics, Nashville, Tenn, USA) and an Apple IIe microcomputer (Apple Computers, Cupertino, Calif, USA) with a HiPad digitising tablet (Houston Instruments Division, Bausch \& Lomb, Austin, Tex, USA). We measured a total of 350 capillary profiles. These included 70 from the WKy control group; 75 from the WKy-galactosaemic group; 60 from the WKy-galactosaemic group fed Sorbinil; 55 from the spontaneously hypertensive control group; 30 from the spontaneously hypertensive-galactosaemic group; and 60 from the spontaneously hypertensive-galactosaemic animals fed Sorbinil. As we have described previously, we measured both "mean (designated here 'average') endothelial basement membrane thickness" by the method of Siperstein et al. [15], or "minimum endothelial basement membrane thickness" using the method of Williamson et al. $[1,16]$, varying these methods in that we included measurements of segments of the endothelial basement membrane that were interposed between endothelial cells and pericyte processes, as well as those portions of the endothelial cell basement membrane that were not covered by pericyte processes. Also, we compared directly measurements of basement membrane thickness, rather than their logarithms, as was done by Williamson, et al. $[1,16]$, for reasons that we have presented earlier [11].

\section{Biochemical procedures}

Determinations of serum glucose were performed using a glucose oxidase method (Glucostat, Worthington Chemical Co., Freehold, NJ, USA). Serum galactose was measured using a galactose oxidase procedure [17]. Levels of Sorbinil were measured in blood serum and in several other tissues by Dr. Robert A. Ronfeld, Pfizer Central Research, Groton, Conn, USA, using a method that has been reported previously [18]. The Sorbinil measurements were carried out on three groups of two 6-month old WKy female rats, and three groups of two 6-month old SHR female rats as follows: (a) control diet; (b) control diet plus $250 \mathrm{mg}$ Sorbinil $/ \mathrm{kg}$ diet; and (c) $30 \%$ galactose plus $250 \mathrm{mg}$ Sorbinil $/ \mathrm{kg}$ diet. These animals were not identical with the experimental rats and were used to prove that Sorbinil actually crosses the blood-brain-barrier as well as the blood retinal barrier. The dietary regimens were maintained for two weeks before death. Basement membrane determinations on these animals are not included in the results presented here. At the time of killing, blood serum was prepared from blood removed by cardiac puncture, retinas and lenses were removed intact from enucleated eyes, and pieces of cortex were dissected from the brains. These tissues were then frozen with dry ice, and shipped to Dr. Ronfeld's laboratory for the Sorbinil assay.

\section{Statistical analysis}

Statistical comparisons utilised the unpaired, two-tailed Student's ttest and, for comparison of nuclear counts, the $\chi^{2}$ test with Yates' correction for continuity.

\section{Results}

The animals fed galactose in these experiments clearly became galactosaemic, since serum galactose levels in these groups (including normotensive and hypertensive rats together) were $3.6 \pm 1.1 \mathrm{mmol} / 1$ mean $\pm \mathrm{SEM}$. There were no significant differences between animals fed Sorbinil, and those that were not; nor were there differences between the normotensive and hypertensive rats. The control groups had a mean serum galactose concentration of $0.17 \pm 0.06 \mathrm{mmol} / \mathrm{l}$. Serum glucose levels showed no significant difference between the control and galactose-fed animals, with mean concentrations of $7.9 \pm 1.6 \mathrm{mmol} / 1$ in the controls and $7.9 \pm 1.8 \mathrm{mmol} / 1$ in the galactose-fed rats. Sorbinil concentrations in WKy and SHR rats maintained for 2 weeks on the various regimens are given in Table 1 . That some drug was detected in tissues of animals on the control diet may be taken as an indication of the limits of the method. Nevertheless, much higher levels were present in animals that received the control diet plus Sorbinil, and the levels were higher still in animals on the galactose-plus-Sorbinil diet.

Our data clearly show that the basement membranes of cerebral cortical capillaries from galactosaemic WKy rats are significantly $(p<0.001)$ thickened by comparison with those from normal controls (Table 2; Fig.1). Cerebral cortical capillary basement membranes from galactosaemic rats that also received Sorbinil demonstrated significantly $(0.001<p<0.01)$ less thickening than those from galactosaemic animals that did not receive the aldose reductase inhibitor. 
Table 1. Sorbinil concentrations in WKy and SHR rats on various dietary regimens for 2 weeks

\begin{tabular}{lllll}
\hline $\begin{array}{l}\text { Group } \\
\text { Animal no. }\end{array}$ & Serum & $\begin{array}{l}\text { Cerebral } \\
\text { cortex } \\
(\mu \mathrm{g} / \mathrm{g})\end{array}$ & $\begin{array}{l}\text { Lens } \\
(\mu \mathrm{g} / \mathrm{g})\end{array}$ & $\begin{array}{l}\text { Retina } \\
(\mu \mathrm{g} / \mathrm{g})\end{array}$ \\
\hline WKy control & $(\mu \mathrm{g} / \mathrm{ml})$ & & \\
$\quad 1$ & 0.00 & 0.10 & 0.00 & 0.20 \\
2 & 0.00 & 0.00 & 0.00 & 0.88 \\
WKy+Sorbinil & & & & \\
$\quad 1$ & 1.29 & 1.12 & 2.40 & 1.57 \\
2 & 2.12 & 2.57 & 2.94 & 2.03 \\
WKy+30\% galactose & & & & \\
+ Sorbinil & & & & \\
$\quad 1$ & 4.68 & 4.21 & 4.74 & 3.88 \\
2 & 4.20 & 3.96 & 5.04 & 3.36 \\
SHR control & & & & \\
$\quad 1$ & 0.00 & Trace & 0.00 & 0.53 \\
2 & 0.00 & 0.86 & 0.00 & 0.45 \\
SHR+ Sorbinil & & & & \\
$\quad 1$ & 1.64 & 1.58 & 2.53 & 1.91 \\
2 & 1.10 & 1.06 & 2.12 & 0.86 \\
SHR+30\% galactose & & & & \\
+ Sorbinil & & & & \\
1 & 2.67 & 2.71 & 5.01 & 3.18 \\
2 & 3.32 & 3.29 & 5.00 & 1.87 \\
\hline
\end{tabular}

Values shown are $\mu \mathrm{g} \mathrm{drug} / \mathrm{ml}$ serum, or $\mu \mathrm{g} \mathrm{drug} / \mathrm{mg}$ wet weight of tissue. Since there were only two animals in each experimental group, individual values, rather than averages, are given

Table 2. Basement membrane thickness (BMT) in electron micrographs of capillaries from frontal cortex of normotensive WistarKyoto (WKy) and spontaneously hypertensive (SHR) rats

\begin{tabular}{|c|c|c|c|}
\hline & $n$ & $\begin{array}{l}\text { Average } \\
\text { BMT } \\
(\text { mean } \pm S D)\end{array}$ & $\begin{array}{l}\text { Minimum } \\
\text { BMT } \\
(\text { mean } \pm S D)\end{array}$ \\
\hline WKy control & 7 & $1518 \pm 102^{\mathrm{a}}$ & $751 \pm 90^{\mathrm{a} d}$ \\
\hline WKy $+30 \%$ galactose & 7 & $1863 \pm 162^{\mathrm{a}, \mathrm{b}}$ & $980 \pm 63^{\mathrm{a}, \mathrm{b}}$ \\
\hline $\begin{array}{l}\text { WKy }+30 \% \text { galactose } \\
\quad+\text { Sorbinil }\end{array}$ & 6 & $1608 \pm 118^{b}$ & $863 \pm 58^{\mathrm{b}, \mathrm{d}}$ \\
\hline SHR control & 5 & $1250 \pm 127^{\mathrm{e}, \mathrm{f}}$ & $621 \pm 177^{\mathrm{c}}$ \\
\hline SHR $+30 \%$ galactose & 3 & $1449 \pm 57^{e}$ & $769 \pm 48$ \\
\hline $\begin{array}{l}\text { SHR }+30 \% \text { galactose } \\
\quad+\text { Sorbinil }\end{array}$ & 6 & $1509 \pm 219^{f}$ & $836 \pm 40^{c}$ \\
\hline
\end{tabular}

BMT values for each vessel were averaged to give mean values for each individual animal. These values were, in turn, averaged to give the mean $\pm S D$ for each group of animals. ${ }^{a} W K y$ control values differ significantly from WKy galactose values, $p<0.001$; ' $\mathrm{WKy}$ galactose values differ significantly from WKy galactose + Sorbinil values, $0.001<p<0.01$; 'SHR control value differs from SHR galactose + Sorbinil value (minimum BMT method), $0.01<p<0.02$; d, e, fWKy control value differs from WKy galactose + Sorbinil value (minimum BMT method); SHR control value differs from SHR galactose value (average BMT method); and SHR control differs from SHR galactose + Sorbinil (average BMT method), $0.02<p<0.05$

However, galactosaemic WKy rats that received Sorbinil had slightly greater cerebral cortical basement membrane thickness than the controls. This difference was significant $(0.02<p<0.05)$ only when the "mini- mum basement membrane thickness" measurement protocol [16] was used.

Cerebral cortical basement membranes from the galactosaemic spontaneously hypertensive rats were significantly $(0.02<p<0.05)$ thicker than those from the hypertensive animals that received the control diet only when the "mean (average) basement membrane thickness" measurement protocol [15] was used. However, the data are incomplete in this group of animals since cerebral cortical tissue from only three of the original six rats in the galactosaemic spontaneously hypertensive group [11] was available for measurement. Also different from our previous data on the retinal vessels [11], Sorbinil did not prevent basement membrane thickening in cerebral capillary basement membranes of spontaneously hypertensive rats that received this drug, together with a galactosaemic diet.

Counts of pericyte and endothelial cell nuclei (Table 3) show no significant differences in the ratios of these two types of nuclei among groups of animals on the various dietary regimens. The ratios of pericyte to endothelial cell nuclei in the frontal cortex of WKy and SHR rats are substantially smaller than the ratio of $1: 3$ that we (using these same WKy and SHR rats [11]) and Tilton et al. (using another strain [19]) have reported for the retinal capillaries of the rat. The number of nuclei counted in this study is rather small and the frequency of nuclei per capillary profile evaluated varies widely in the different groups of rats. However, pericyte processes were present in nearly every capillary profile we observed. We encountered none, in any of the thin sections from any of the animal groups, that showed any evidence of cellular degeneration.

\section{Discussion}

Our results suggest that capillary basement membrane thickening induced by galactosaemia in rats may be a generalised lesion since it occurs in at least two organs, the retina and the cerebral cortex. In this it is similar to diabetes mellitus in humans which has also been reported in capillaries of the cerebral cortex [5] as well as the retina [3] and other [1,2] tissues.

The values that we report here are averaged for animals of different ages. This appears to be a valid method, since the numbers of animals in each experimental group were nearly equally distributed at the different ages so that no age bias was introduced. Although basement membrane thickness increases with age in normal animals $[1,3]$, as we have demonstrated previously for the retinal capillaries of the rat [11], capillary basement membrane thickness values in each age group are much greater in animals fed the $30 \%$ galactose diet. A similar relationship between age and basement membrane thickness exists for cerebral cortical capillaries in WKy and SHR rats ([20] and unpublished observations of the authors). 


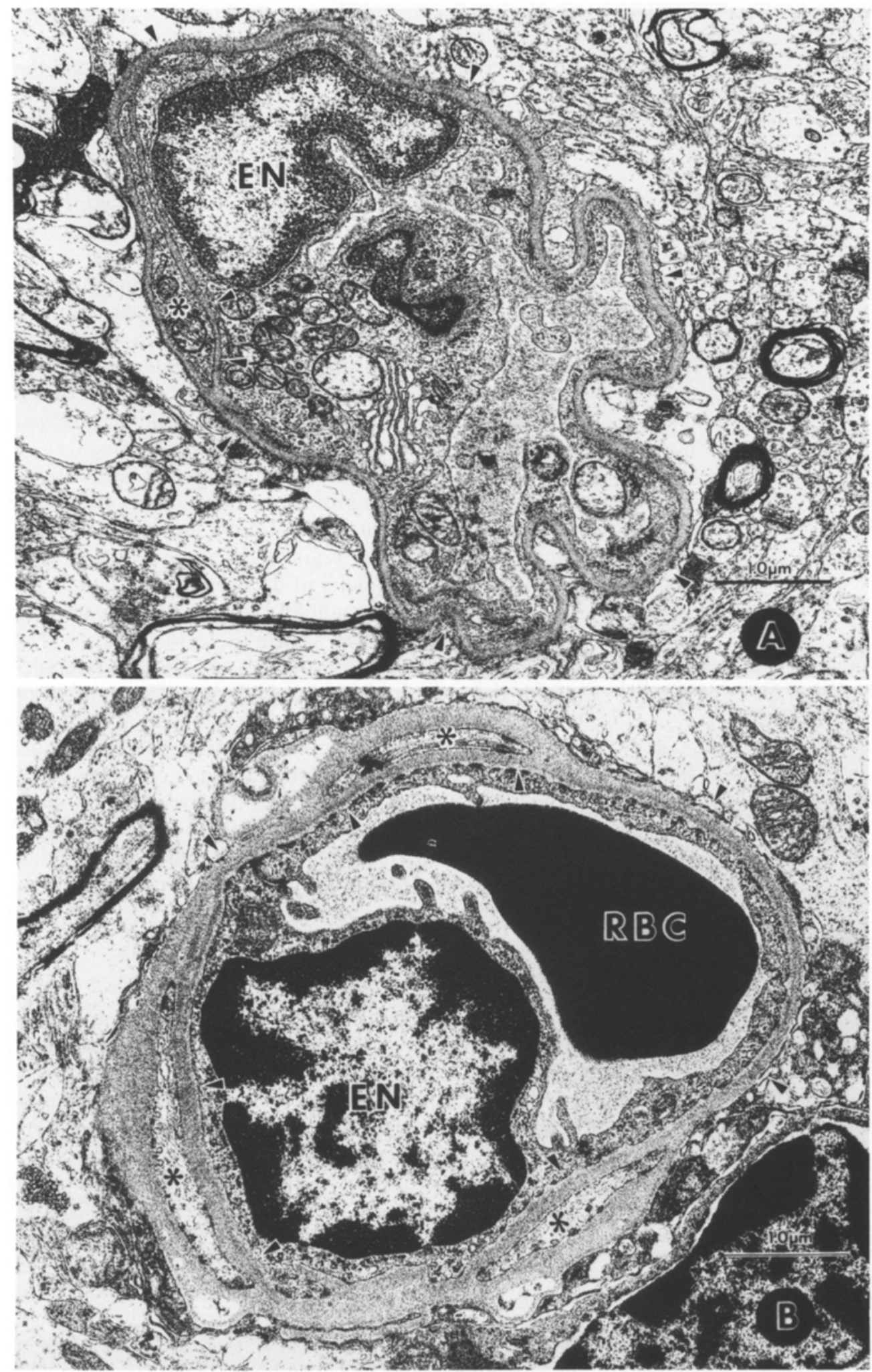

Fig. 1. a A capillary with normal basement membrane thickness from the frontal cortex of a 21-month old Wistar-Kyoto rat. Closed arrowheads mark the endothelial basement membrane, whose thickness is measured in our protocol. The thickness of the basement membrane on the outer (abluminal) surface of a pericyte process, which is marked with an asterisk $(*)$, is not measured, but thickness of the basement membrane which lies between the pericyte process and the endothelial cell is measured. An endothelial cell nucleus is indicated by EN. The calibration bar $=1.0 \mu \mathrm{m}$. b A capillary from the frontal cortex of a WKy rat which had been fed a diet containing $30 \%$ galactose for 15 months. Note the thickening of both the endothelial cell and the pericyte basement membranes (the latter is not measured in these experiments). The endothelial basement membrane is indicated by closes arrowheads. Pericyte processes are indicated by asterisks $(*)$. An endothelial cell nucleus is denoted by $E N$, and an erythrocyte within the capillary lumen by RBC. Note the clear vacuoles within the basement membrane. The calibration bar $=1.0 \mu \mathrm{m}$

Contrasting with the results that we [11] and others [12] have presented for the retinal microvessels of the rat, our present data show a somewhat lessened (in the WKy rats), or no (in the SHR rats) effect of the aldose reductase inhibitor Sorbinil in preventing galactose-induced cerebral microvascular basement membrane thickening. This is unexpected in view of our previously published results. The present data cannot be explained by a difference in the "barrier" function to Sorbinil between blood and retina, and blood and brain, in these animals because drug concentrations in retina and cerebral cortex, as well as lens, were at least 
Table 3. Pericyte and endothelial cell nuclear counts in electron micrographs of cerebral cortical capillaries of normotensive Wistar Kyoto (WKy) and spontaneously hypertensive (SHR) rats

\begin{tabular}{lcc}
\hline & $\begin{array}{l}\text { Pericyte } \\
\text { nuclei }\end{array}$ & $\begin{array}{l}\text { Endothelial cell } \\
\text { nuclei }\end{array}$ \\
\hline WKy control & 1 & 26 \\
WKy $+30 \%$ galactose & 4 & 40 \\
WKy galactose + Sorbinil & 4 & 36 \\
\hline Total & 9 & 102 \\
SHR control & 3 & 8 \\
SHR + 30\% galactose & 4 & 22 \\
SHR + galactose + Sorbinil & 4 & 22 \\
\hline Total & 11 & 52
\end{tabular}

There are no significant differences in ratios of pericyte and endothelial nuclei among the different groups of WKy and SHR rats, using the $\chi^{2}$ test with Yates' correction for continuity

equal to those in serum. Since the fractional volume of blood in the retinal and cortical samples is quite small (and is zero in the avascular lens) this result means that Sorbinil must cross the circulatory barriers to enter these tissues. (The higher levels of Sorbinil in both serum and tissues in galactosaemic animals remains unexplained.) However, other possibilities may exist to explain our results. For example, access of the drug to binding sites on the enzyme may be limited in the brain or binding sites to inhibitor molecules may differ for the brain enzyme.

As we have also demonstrated in the retinal microvessels, chronic galactosaemia does not cause degeneration of cerebral microvessel pericytes in the rat, at least over this relatively short period of observation. Our results in this regard differ from those recently reported in streptozotocin-diabetic SHR and WKy rats by Junker et al. [20], who reported more pericyte degeneration in capillaries from the frontal cortex and hypothalamus of these animals than in nondiabetic control rats. Surprisingly, in view of these rather dramatic results, the rats described by these authors were much younger than ours (they entered the study at virtually identical body weights and initial ages as our animals, and were killed after only 4 to 8 months of diabetes), and their cerebral capillary basement membranes were much thinner.

Differing from the retina, in which nuclear counts from electron micrographs of retinas from several different strains of rats show a ratio of 1 pericyte to 3 endothelial cells [11, 19], the pericyte-to-endothelial cell ratio in the frontal cortex of WKy and SHR rats is substantially less, and also differs considerably in the two strains (Table 3). We have shown elsewhere by electron microscope morphometric methods [21] that coverage of the capillary circumference by the pericyte cell body and processes is also significantly less in several different regions of the cerebral cortex of the rat than in the retina. This anatomic difference between the retinal and cerebral microvessels of the rat has an important consequence in light of the present results. Akagi et al. [22] have demonstrated in the human retina that only the pericytes are immunocytochemically positive for aldose reductase. This might be taken to imply a causal relationship between aldose reductase activity in pericytes and their degeneration in retinal and other capillaries of diabetic individuals [23, 24], as well as the capillary basement membrane thickening observed in galactosaemic rats that also appears to be related to the activity of this enzyme [11-13]. However, there is a much lower ratio of pericytes to endothelial cells in the frontal cortex of the rat cerebrum than in the retina. Consequently, there is a much larger endothelial surface in rat cerebral microvessels that is not covered by pericyte processes or cell bodies than in the microvessels of the rat retina. It is therefore difficult to imagine how the basement membrane thickening that we have observed in the cerebral cortical capillaries of galactosaemic rats can be produced by an enzyme activity that is located solely in the pericytes.

In summary, our results show that experimental galactosaemia produces significant capillary basement membrane thickening in the frontal cortex of the cerebrum of Wistar-Kyoto rats, just as it does in the retinal capillaries of these animals. This basement membrane thickening is largely prevented by simultaneous feeding of the aldose reductase inhibitor, Sorbinil. A lesser degree of basement membrane thickening that is not prevented by Sorbinil appears to be present in galactosaemic, spontaneously hypertensive rats. These findings may yet be consistent with a causal role for aldose reductase in galactosaemic (and quite likely also diabetic) vascular basement membrane thickening. However, in view of the relative paucity of pericytes in the capillaries of the frontal cerebral cortex of the rat by comparison with the capillaries of the retina, it is difficult to reconcile our results with a role for the aldose reductase that is reportedly specifically localised to the pericytes in the pathogenesis of this basement membrane thickening.

Acknowledgments. This study was supported in part by a grant (RO1 EY02566) from the US National Institutes of Health to RNF, and by a departmental unrestricted grant from Research to Prevent Blindness, New York. We thank Mr. M.A. Mancini, Mr. A. Kennedy, and Ms. J. Khoury for technical assistance, and Ms. A. Fisher for secretarial assistance.

\section{References}

1. Kilo C, Vogler N, Williamson JR (1972) Muscle capillary basement membrane changes related to aging and to diabetes mellitus. Diabetes 21: 881-905

2. Osterby R (1975) Early phases in the development of diabetic glomerulopathy. Acta Med Scand [Suppl] 574: 1-80

3. Bloodworth JMB Jr (1967) Fine structure of retina in human and canine diabetes mellitus. In: Kimura SJ, Caygill WM (eds) Vascular complications of diabetes mellitus. CV Mosby, St.Louis, pp 73-86 
4. Yamashita T, Becker B (1961) The basement membrane in the human diabetic eye. Diabetes 10: 167-174

5. Johnson PC, Brendel K, Meezan E (1982) Thickened cerebral cortical capillary basement membranes in diabetics. Arch Pathol Lab Med 106: 214-217

6. Johnson PC, Brendel K, Meezan E (1981) Human diabetic perineurial cell basement membrane thickening. Lab Invest 44: $265-270$

7. Leuenberger PM, Beauchemin ML, Babel J (1974) Experimental diabetic retinopathy. Arch Ophtalmol (Paris) 34: 289-302

8. Fischer F, Gärtner J (1983) Morphometric analysis of basal laminae in rats with long-term streptozotocin diabetes. II. Retinal capillaries. Exp Eye Res 37: 55-64

9. Bloodworth JMB, Engerman RL, Camerini-Dávalos RA, Powers KL (1970) Variations in capillary basement membrane width produced by aging and diabetes mellitus. In: Camerini-Dávalos RA and Cole HF (eds) Early diabetes. (Advances in metabolic disorders, Suppl 1) Academic Press, New York, pp 279-288

10. Engerman RL, Colquhoun PJ (1982) Epithelial and mesothelial basement membranes in diabetic patients and dogs. Diabetologia 23: $521-524$

11. Frank RN, Keirn RJ, Kennedy A, Frank KW (1983) Galactoseinduced retinal capillary basement membrane thickening: prevention by Sorbinil. Invest Ophthalmol Vis Sci 24: 1519-1524

12. Robison WG Jr, Kador PF, Kinoshita JH (1983) Retinal capillaries: basement membrane thickening by galactosemia prevented with aldose reductase inhibitor. Science 221: 1177-1179

13. Robison WG Jr, Kador PF, Akagi Y, Kinoshita JH, Gonzalez R, Dvornik D (1986) Prevention of basement membrane thickening in retinal capillaries by a novel inhibitor of aldose reductase, Tolrestat. Diabetes 35: 295-299

14. Engerman RL, Kern TS (1984) Experimental galactosemia produces diabetic-like retinopathy. Diabetes 33: 97-100

15. Siperstein MD, Unger RH, Madison LL (1986) Studies of muscle capillary basement membranes in normal subjects, diabetic, and prediabetic patients. J Clin Invest 47: 1973-1999
16. Williamson JR, Vogler NJ, Kilo C (1969) Estimation of vascular basement membrane thickness: theoretical and practical considerations. Diabetes 18: $567-578$

17. Hjelm M, Tengström B (1968) Enzymatic determinations of blood galactose with galactose oxidase and galactose dehydrogenase. Biochem Med 2: 174-176

18. Foulds G, O'Brien MM, Bianchine JR, Gabbay KH (1981) Kinetics of an orally absorbed aldose reductase inhibitor, sorbinil. Clin Pharm Ther 30: 693-700

19. Tilton RG, Miller EJ, Kílo C, Williamson JR (1985) Pericyte form and distribution in rat retinal and uveal capillaries. Invest Ophthalmol Vis Sci 26: 68-73

20. Junker U, Jaggi C, Bestetti G, Rossi GL (1985) Basement membrane of hypothalamus and cortex capillaries from normotensive and spontaneously hypertensive rats with streptozotocin-induced diabetes. Acta Neuropathol 65: 202-208

21. Frank RN, Dutta S, Mancini MA (1987) Pericyte coverage is greater in the retinal than in the cerebral capillaries of the rat. Invest Ophthalmol Vis Sci 28: 1086-1091

22. Akagi Y, Kador PF, Kuwabara T, Kinoshita JH (1983) Aldose reductase localization in human retinal mural cells. Invest Ophthalmol Vis Sci 24: 1516-1519

23. Cogan DG, Toussaint D, Kuwabara T (1961) Retinal vascular patterns. IV. Diabetic retinopathy. Arch Ophthalmol 66: 366-378

24. Tilton RG, Hoffman PL, Kilo C, Williamson JR (1981) Pericyte degeneration and basement membrane thickening in skeletal muscle capillaries of human diabetics. Diabetes 30: 326-334

Received: 1 December 1986

and in revised form: 29 July 1987

Dr. R. N. Frank

Kresge Eye Institute of Wayne State University School of Medicine 3994 John R Street

Detroit, MI 48201

USA 